\title{
Protein Kinase D1 Signaling in Angiogenic Gene Expression and VEGF-Mediated Angiogenesis
}

\author{
Bin Ren ${ }^{1,2 *}$ \\ ${ }^{1}$ Department of Medicine, Medical College of Wisconsin, Milwaukee, WI, USA, ${ }^{2}$ Blood Research Institute, Blood Center of \\ Wisconsin, Milwaukee, WI, USA
}

Protein kinase $D 1$ (PKD-1) is a signaling kinase important in fundamental cell functions including migration, proliferation, and differentiation. PKD-1 is also a key regulator of gene expression and angiogenesis that is essential for cardiovascular development and tumor progression. Further understanding molecular aspects of PKD-1 signaling in the regulation of angiogenesis may have translational implications in obesity, cardiovascular disease, and cancer. The author will summarize and provide the insights into molecular mechanisms by which PKD-1 regulates transcriptional expression of angiogenic genes,

OPEN ACCESS

Edited by:

Jiri Novotny,

Charles University in Prague,

Czech Republic

Reviewed by:

Yanyong Kang,

Van Andel Institute, USA

Ignacio Rodriguez-Crespo,

Universidad Complutense de Madrid,

Spain

${ }^{*}$ Correspondence:

Bin Ren

bren@mcw.edu;

ren.science@gmail.com

Specialty section:

This article was submitted to

Signaling,

a section of the journal

Frontiers in Cell and Developmental

Biology

Received: 13 January 2016 Accepted: 18 April 2016

Published: 04 May 2016

Citation:

Ren B (2016) Protein Kinase D1 Signaling in Angiogenic Gene

Expression and VEGF-Mediated

Angiogenesis.

Front. Cell Dev. Biol. 4:37.

doi: 10.3389/fcell.2016.00037 focusing on the transcriptional regulation of CD36 by PKD-1-FoxO1 signaling axis along with the potential implications of this axis in arterial differentiation and morphogenesis. He will also discuss a new concept of dynamic balance between proangiogenic and antiangiogenic signaling in determining angiogenic switch, and stress how PKD-1 signaling regulates VEGF signaling-mediated angiogenesis.

Keywords: protein kinase D, CD36, VEGF, gene expression, transcription, endothelial cells, angiogenesis, arteriogenesis

\section{INTRODUCTION}

The protein kinase PKD $(P R K D)$ is a serine threonine kinase consisting of three isoforms PKD-1,-2, and -3 (Rykx et al., 2003; Evans et al., 2010). Different PKD family members have unique and nonredundant roles. PKD-1 is essential for normal embryogenesis while PKD-2 regulates the functions of mature peripheral lymphocytes during adaptive immune responses (Matthews et al., 2010) and PKD-3 modulates airway epithelial barrier formation, the growth of breast and prostate cancer cells and vesicle trafficking (Anderson et al., 2005; Chen et al., 2008; Huck et al., 2012, 2014). Initially, PKD-1 was classified to an atypical member of protein kinase $\mathrm{C}$ (PKC) family and known as PKCmu. However, this kinase presents a catalytic domain distantly related to $\mathrm{Ca}^{2+}$-regulated kinase and it was thus classified to the calcium/calmodulin-dependent protein kinase superfamily (Manning et al., 2002; Rozengurt et al., 2005).

PKD-1 mRNA is highly expressed in such tissues as the heart, the lungs, and the brain, as well as in a variety of cell types including vascular endothelial cells (VECs), fibroblasts, and dendritic cells. This indicates that PKD-1 is a key regulator in tissue homeostasis and cellular functions. PKD-1 mediates signaling pathways important in cardiovascular diseases, immune functions and cancer (Parra et al., 2005; Fielitz et al., 2008; Ha et al., 2008b; LaValle et al., 2010a,b; Wille et al., 2014). It may be involved in myocardial responses to ischemia and arterial remodeling (Avkiran et al., 2008; Ren et al., 2014, 2015). It also regulates cardiac energy homeostasis by influencing the secretion of cardiac lipoprotein lipase, an enzyme important in controlling heart metabolism in experimental 
diabetes (Wang and Rodrigues, 2015). The studies on lung microvascular ECs (MVECs) indicate that PKD-1 is required for PMA- and DAG-induced phosphorylation of myristoylated alanine-rich PKC substrate and hyperpermeability (Tinsley et al., 2004).

Interestingly, $P R K D 1$ is likely the gene targeted in clinical trials for schizophrenia drugs, implicating its functional significance in the brain functions. The authors suggested that bryostatin, a partial agonist at $\mathrm{PKD}$, represents a promising drug for the treatment of schizophrenia (Lencz and Malhotra, 2015). GWAS studies show that PRKD gene is associated with body mass index (Speliotes et al., 2010; Comuzzie et al., 2012), suggesting the involvement of PKD-1 signaling in the pathobiology of diet-induced obesity (Huang et al., 2013; Dong et al., 2015; Yuan et al., 2015).

In the vascular system, PKD-triggered signaling pathways in ECs appear to process angiogenic information so that ECs respond appropriately to the environmental stimuli. This may be involved in VEGF-stimulated phospholipase C $\gamma 1$ (PLC $\gamma 1$ ) signaling (Wong and Jin, 2005; Qin et al., 2006) and LPAmediated transcriptional repression of CD36 (Ren et al., 2011). In this review, the author will briefly introduce the essential features of PKD-1 in structures and functions. Subsequently, he will discuss regulation of angiogenic gene expression by PKD1 and its biological implications. He will specifically emphasize how CD36 transcription is regulated by $\mathrm{PKD}-1-\mathrm{FoxO} 1$ signaling axis and what this axis implicates in arterial differentiation and morphogenesis. Finally, he will discuss a new concept of dynamic balance between proangiogenic and antiangiogenic signaling in determining angiogenic switch and focus on PKD-1 signaling in the regulation of VEGF-mediated EC functions and angiogenesis

\section{STRUCTURAL FEATURES AND GENERAL FUNCTIONS OF PKD-1}

PKD is encoded by the PRKD1 gene that is located on human chromosome14q11. The gene transcript consists of 18 exons, and encodes a protein with 912 amino acid residues. PKD-1 contains a C-terminal kinase domain and a variable $\mathrm{N}$-terminal regulatory domain with two highly conserved cysteine-rich zinc finger-like motifs (CR1 and CR2) and a pleckstrin homology $(\mathrm{PH})$ domain inserted between the cysteine-rich motif and the catalytic domain. Different from protein kinase $\mathrm{PKC}, \mathrm{PKD}$ contains $\mathrm{PH}$ domain within the regulatory region. The catalytic domain is distantly related to $\mathrm{Ca}^{2+}$-regulated kinase, and a highly hydrophobic stretch of amino acids is located in its N-terminal region (Lint et al., 2002; Rozengurt et al., 2005). The structural characteristics make this kinase unique in the regulation of cellular functions through activating its multiple phosphorylation sites (Figure 1).

PKD-1 remains inactive in cytosol partly through autoinhibition of its catalytic activity by the $\mathrm{PH}$ domain. The multisite phosphorylations of the kinase control its signaling spatiotemporally. The phosphorylation in specific sites changes the catalytic activity and influences docking interactions with cellular scaffolds and trafficking to signaling microdomains in the subcellular compartments (Steinberg, 2012). G-protein subunits $\beta \gamma$ directly interacts with the $\mathrm{PH}$ domain to activate the kinase by releasing the auto-inhibition of catalytic domain (Jamora et al., 1999; Waldron and Rozengurt, 2003). Once PKD-1 is stimulated by engaging $\mathrm{G}$ protein-coupled receptors (GPCRs) in response to growth factor signaling or oxidative stress, the molecules are able to be translocated to the plasma membrane. In the plasma membrane they are phosphorylated and activated. However, these molecules will ultimately be accumulated in the nucleus (Matthews et al., 2000) while its subcellular localization is regulated by the $\mathrm{N}$-terminal domain, and the zinc fingerlike motifs in particular (Rykx et al., 2003). The major catalytic sites are located at ser-744 and ser-748 or ser-738 and ser-742 within the activation loop of the catalytic domain, respectively in mouse and human PKD-1 (Iglesias et al., 1998) and in ser-916 (Matthews et al., 1999; Rozengurt et al., 2005). The phosphorylation activates $\mathrm{PKD}-1$, whereas binding to 14-3-3 or chaperon protein p32 decreases its activity. Additionally, in response to apoptosis inducing agents, PKD-1 undergoes cleavage, releasing a $62 \mathrm{kD}$ catalytic fragment by caspase 3 (Endo et al., 2000).

PKD-1 signaling functions downstream of PLC $\gamma 1$, GPCRs, and tyrosine kinase receptors. The signaling activation phosphorylates downstream targets at specific sites, thereby regulating subcellular localization and/or its activity (Rozengurt,

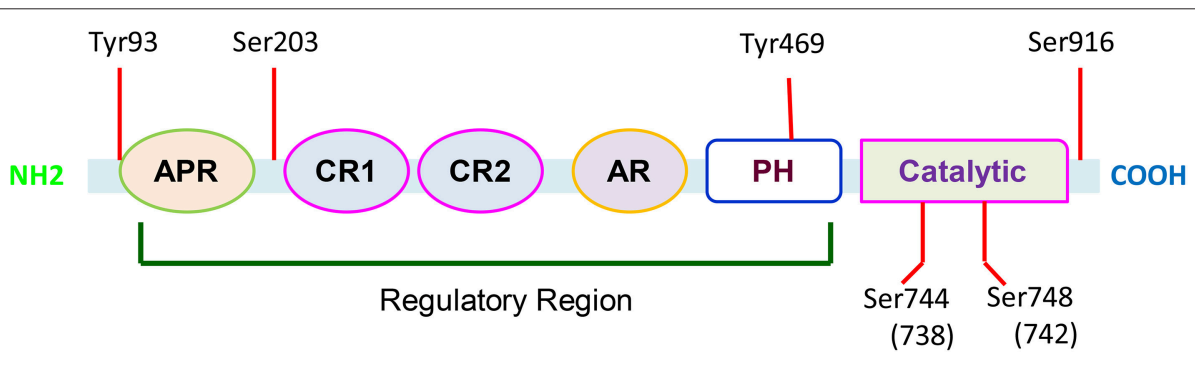

FIGURE 1 | Functional domains of PKD-1. PKD-1 contains multiple functional domains including alanine and proline rich domain (APR); cysteine-rich, zinc finger-like domains (CR1 and CR2); acidic-rich region (AR); and pleckstrin homology domains (PH). There are six conserved phosphorylation sites. In response to a variety of biological factors, these sites can be phosphorylated to activate PKD-1 and regulate fundamental cellular functions. 
2011) and the cellular processes such as DNA synthesis, proliferation, and invasion/migration (LaValle et al., 2010b). Importantly, PKD-1 signaling locates upstream of PI3K-Akt and MAPK/Erk1/2 signaling pathways (Guha et al., 2010) and is able to induce NF-kB activity in cells exposed to GPCR agonists or oxidative stress (Storz et al., 2005), which implicates the central roles of this kinase in EC functions and arteriogenesis (Ren et al., 2010, 2015; Tirziu et al., 2012).

\section{REGULATION OF TRANSCRIPTIONAL EXPRESSION OF ANGIOGENIC GENES BY PKD-1}

Gene expression controls cellular phenotypes. Different cell types express characteristic sets of transcriptional regulators, thus controlling the expression of cellular specific genes through turning specific combinations of regulators on and off. The gene regulation drives the processes of cellular differentiation and morphogenesis to produce different cell types that possess varying gene expression profiles. The differential expression of angiogenic genes is critical in EC heterogeneity and angiogenesis (Adams and Alitalo, 2007; Aird, 2012; Ren, 2015; Yuan et al., 2016).

More and more studies show that PKD-1 signaling regulates the transcriptional expression of genes that are important in angiogenesis. The early growth response 3 (Egr3) is a member of a zinc-finger-like transcription factor subfamily. VEGF activates PKD-1 via the VEGFR2/KDR-PKC signaling, and subsequently induces Egr-dependent transcriptional activation and Egr3 expression (Liu et al., 2008), whereas inhibition of Egr3 expression decreases VEGF-mediated EC proliferation, migration and tubulogenesis (Liu et al., 2008). Recently, Zhao et al. showed that the calcium-PLC-PKC-PKD-1 pathway regulates VEGF-induced mRNA expression of TR3-TV2 and TR3-TV3 (Zhao et al., 2014). PKD-1/HDAC7/MEF2 signaling together with Erk1/2 pathway also regulates VEGF-induced Nur77 expression during VEGF-induced EC activation (Ismail et al., 2012).

\section{PKD-1 Interaction with Histone Deacetylases to Regulate Angiogenic Gene Expression}

Histone acetylation/deacetylation regulates transcriptional expression of genes through a dynamic balance between histone acetyltransferases and histone deacetylases (HDACs). HDACs are critical to inhibiting acetylation of nucleosome histones. Interestingly, HDAC5 and HDAC7, highly expressed in ECs (Mottet et al., 2007; Altschmied and Haendeler, 2008), are the substrate of PKD-1 (Avkiran et al., 2008) and regulate EC functions and angiogenesis (Wang et al., 2008; Urbich et al., 2009). VEGF stimulates HDAC5 phosphorylation and nuclear export in ECs via a VEGFR2-PLC $\gamma$-PKD-dependent pathway. Moreover, PKD-1 signaling interacts with HDAC5 to promote transcriptional activation of myocyte enhancer factor-2 (MEF2) and a specific subset of gene expression in response to VEGF including NR4A1, an orphan nuclear receptor involved in angiogenesis (Ha et al., 2008b). VEGF-mediated PKD-1 signaling also stimulates HDAC7 phosphorylation and cytoplasmic accumulation, thus modulating the expression of HDAC7-targeting and VEGF-response genes as well as VEGF-stimulated EC migration, tube formation, and sprouting angiogenesis (Mottet et al., 2007; Ha et al., 2008a). A similar mechanism is involved in the induction of PDGF-B/PDGFR- $\beta$ expression and subsequent proangiogenic responses (Mottet et al., 2007). These studies indicate that PKD-1 interacts with specific HDACs to function as a molecular switch for controlling angiogenic gene transcription and VEGF-mediated angiogenesis.

\section{Regulation of Arteriogenic Gene Expression by PKD-1 in Microvascular Endothelial Cells}

In primary MVECs, the lysophosphatidic acid (LPA), a lipid signaling mediator, regulates angiogenesis in a chicken chorioallantoic membrane assay and in vivo Matrigel assay (Rivera-Lopez et al., 2008; Ren et al., 2011) and promotes breast cancer angiogenesis in diet-induced obesity (Dong et al., 2015). LPA/PKD-1 signaling-mediated CD36 transcriptional repression is important in angiogenic processes (Ren et al., 2011). We found that PKD-1 signaling in MVECs promotes nuclear accumulation of HDAC7 in response to LPA (Ren et al., 2014), which is different from a previous report in HUVECs exposed to VEGF (Ha et al., 2008a). This indicates that a PKD1 signaling "signature" is different in a specific cellular context. In certain cellular microenvironments, PKD-1 determines the formation of nuclear regulatory complex and aids in gene locusspecific nucleosomal enrichment of specific histone deacetylase (Fu and Rubin, 2011). PKD-1 may mediate HDAC7-FoxO1 interaction in the nucleus (Ren et al., 2014, 2015) and maintain context relevant EC functions via FoxO1-dependent regulation of CD36 transcription in HMVECs rather than via MEF-2dependent regulation of matrix metalloprotease (Chang et al., 2006).

HDAC7 is an established regulator of chromatin structure and gene transcription (Haberland et al., 2009) and of angiogenesis (Chang et al., 2006; Mottet et al., 2007; Ha et al., 2008a). HDAC7regulated gene repression and de-repression are indispensable for angiogenic functions (Ha et al., 2008a; Wang et al., 2008). In MVECs LPA/PKD-1 signaling appears to control the FoxO1 transcriptional switch (Hamik et al., 2006) via mediating the formation of a nuclear complex comprised of FoxO1 and HDAC7. PKD-1 signaling activation might specifically turn off the FoxO1 switch in the CD36 gene locus for suppressing CD36 transcription, whereas arteriogenic gene reprogramming is initiated once CD36 transcription is turned off in response to LPA (Ren et al., 2015). This may be associated with the proarteriogenic responses in a tumor microenvironment (Kohlenberg et al., 2013). These findings suggest that PKD-1 signaling epigenetically regulates arteriogenic gene transcription via modulation of chromatin remodeling and is involved in microvascular remodeling. 


\section{PKD-1 FUNCTIONS IN VEGF SIGNALING AND ANGIOGENESIS}

\section{Basic Concept of Angiogenesis}

Angiogenesis is a physiological or pathological process from which new blood vessels develop from pre-existing vessels, and in which ECs is the key (Carmeliet, 2000; Semenza, 2007; Ren, 2015). Physiological angiogenesis is fundamental for development, reproduction, and tissue repair, whereas pathological angiogenesis leads to aberrant neovascularization due to uncontrolled EC activity and contributes to ischemic cardiovascular disease, rheumatoid arthritis, and cancer (Carmeliet, 2000). The plaque angiogenesis is of functional significance in atherosclerosis (Moulton et al., 2003, 2004), and occurs more frequently in atheromas of patients with diabetes and unstable coronary syndromes (Burke et al., 1997). Antiangiogenic endostatin could thus control the progression of atherosclerosis by inhibiting plaque angiogenesis (Moulton et al., 1999; Ren et al., 2002, 2003).

Angiogenesis is controlled by biological and physical interactions between cells and extracellular matrices. Biological and mechanical signals integrate with other microenvironmental cues to control angiogenesis via a dynamic signaling balance between pro- and anti-angiogenic factors, while the dominant signaling determines the on and off of the angiogenic switch (Ren et al., 2006, 2009; Chen et al., 2013; Ren, 2015).

Currently, the majority of the research focuses on pro- and anti-angiogenic factors to regulate angiogenic switch (Bergers and Benjamin, 2003). Actually, the Yin and Yang balance between pro- and anti-angiogenic signaling may control the angiogenic switch. This dynamic signaling balance could play a critical role in the regulation of pathophysiological and physiological angiogenesis. Moreover, the angiogenic receptors may serve as a pivotal axis to regulate this angiogenic process. The ligand and receptor interactions are the key to integrating signaling for the regulation of angiogenic switch. A good example is a yin and yang balance between antiangiogenic TSP-1 and proangiogenic VEGF signaling which determines angiogenic switch, and in which PKD-1 is a key player. PKD-1 functions downstream of VEGF/PLC $\gamma 1$ signaling to stimulate angiogenesis. LPA, a lipid signaling mediator, may suppress CD36 expression via PKD-1 and regulate crosstalk between VEGFR2 and CD36, subsequently contributing to angiogenic switch (Figure 2). VEGF is essential for angiogenesis due to its regulation of biological responses in ECs during development and in disease, while TSP-1CD36 signaling could crosstalk with VEGF signaling to control arteriogenic fate and angiogenic responses.

\section{PKD-1 in VEGF Signaling-Mediated EC Functions}

ECs is a key player in angiogenesis (Ren, 2015). VEGF signaling in ECs is regulated at multiple levels via three receptor tyrosine kinases or VEGF receptor 1-3 (VEGFR1-3). VEGF interactions with VEGFR2/KDR (kinase insert domain receptor) are critical for normal blood vessel development (Matsumoto and Claesson-Welsh, 2001; Folkman and Kalluri, 2004) and

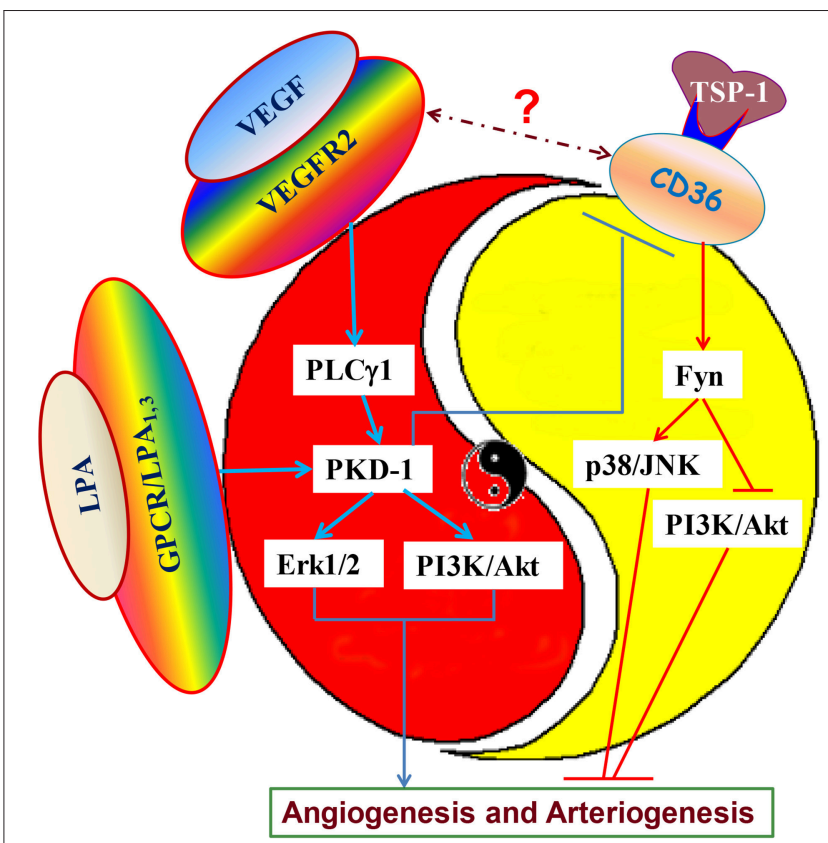

FIGURE 2 | Dynamic angiogenic signaling balance and angiogenic switch. VEGF, as an important angiogenic cytokine, is critical for proangiogenesis, and proarteriogenesis via activating VEGF receptor 2. VEGF signaling via VEGF receptor 2 can activate PKD-1 pathway via PLC $\gamma 1$ to stimulate MAPK/Erk1/2 and PI3K/Akt activation. However, oncogenes, such as ras and myc or tumor suppressor gene p53 down-regulate or up-regulate TSP-1 expression, and affect TSP-1 interaction with the CD36 receptor, altering the activities of Fyn, p38/JNK, and PI3K/Akt kinases. This interaction may produce disturbances in the dynamic signaling balance between angiogenesis stimulators and inhibitors. The dominant signaling will determine the angiogenic switch. LPA also activates PKD-1 signaling to suppress CD36 transcription to tip the signaling balance to VEGF-mediated proangiogenic and proarteriogenic responses. Inhibition of CD36 expression and its anti-angiogenic signaling can prime VEGF signaling for turning on the proangiogenic and proarteriogenic switch for angiogenesis and arteriogenesis.

deregulates in pathological conditions (Wong et al., 2001; Ferrara et al., 2003). VEGFR-2-mediated VEGF signaling is also important in proangiogenic responses, including EC migration, proliferation and tubulogenesis, the key biological processes in angiogenesis (Wang, 2006; Evans et al., 2008).

PKD-1 signaling plays a key role in those processes in addition to its roles in regulation of EC survival, trafficking and immune response (Prigozhina and Waterman-Storer, 2004; Yeaman et al., 2004; Wang, 2006; Eiseler et al., 2007; von Wichert et al., 2008). VEGF activates PKD-1 via the VEGFR2/PLC $\gamma / \mathrm{PKC} \alpha$ pathway, promoting Erk activation and DNA synthesis for EC proliferation (Wong and Jin, 2005). PKD-1 phosphorylation at tyrosine 463 by VEGF can activate PLC $\gamma$ to stimulate proangiogenic responses (Qin et al., 2006) and activate Erk1/2 signaling (Kohlenberg et al., 2013), implicating its function in arterial differentiation (Lawson et al., 2003; Hong et al., 2006; Ren et al., 2015).

PKD-1 regulates collagen I-induced vascular morphogenesis via modulating GSK $3 \beta$ activity and integrin $\alpha(2) \beta(1)$ trafficking (Shin et al., 2012), whereas PKD-1-mediated integrin $\alpha \mathrm{v} \beta 3$ trafficking contributes to the angiogenic process by integrating and coordinating EC activity (di Blasio et al., 2010). These 
studies suggest that this kinase mediates the bidirectional communication between VEGFR and integrins. Furthermore, PKD-1 regulates VEGF-mediated host inflammatory responses and could lead to inflammatory angiogenesis. PKD-1 signaling is associated with VEGF-induced expression of proinflammatory cytokines via VEGFR2 including interleukin (IL)-6, CXC chemokines IL-8, and growth-related oncogene-alpha (GROalpha; Hao et al., 2009a). Additionally, PKD-1 interacts with heat shock proteins (HSPs) to regulate angiogenesis. PKCmediated PKD-1 signaling regulates VEGF-induced HSP 27 phosphorylation at phosphorylation site serine 82 and tubulogenesis in HUVECs (Evans et al., 2008). Recently, PKD-1 was shown to activate endothelial nitric oxide synthase and orchestrate mammalian vascular tone through phosphorylation, concomitantly increasing NO synthesis. Inhibition of the kinase activity in mice abolishes VEGF-induced vasodilatation, indicating that PKD-1 is the key to transducing VEGF signaling for VEGF-induced vasodilatation (Aicart-Ramos et al., 2014). These studies suggest that PKD-1 signaling may regulate EC cross-talking with other cell types, such as vascular smooth muscle cells, via producing signaling molecules in the tissue microenvironments. Interestingly, the isoform PKD2 also regulates proliferation and migration in HUVECs, the two important process of angiogenesis, and this may be mediated by modulation of the expression of VEGFR-2 and fibroblast growth factor receptor-1 (Hao et al., 2009b).

\section{PKD Signaling in Tumor Angiogenesis}

Tumor angiogenesis is critical, not only in rapidly growing macroscopic tumors, but also in microscopic premalignant phase of neoplastic progression, and thus is considered as an integral hallmark of cancer (Hanahan and Weinberg, 2011). Emerging studies have begun to focus on PKD functions in tumor angiogenesis.

PKDs regulate both hypoxia-induced VEGF expression/secretion by the tumor cells and VEGF- stimulated angiogenesis, which are essential for the malignant progression of tumors. Studies show that PKD-1 promotes anchorageindependent growth, invasion, and angiogenesis in human pancreatic cancer including PDAC (Guha et al., 2010; Ochi et al., 2011). In a zebrafish/tumor xenograft model, this kinase is shown to promote angiogenesis and malignant progression (Hollenbach et al., 2013). Our study implicates that diet-induced obesity may promote tumor progression via LPA/PKD-1 signaling-mediated angiogenesis (Dong et al., 2015). Interestingly, PKD-1 signaling appears to regulate tumor angiogenesis and is implicated in tumor arteriogenesis as it may regulate CD36 expression and vascular remodeling in the tumor microenvionment (Kohlenberg et al., 2013).

The PKD-2 also mediates production of various angiogenic factors in human pancreatic cancer cells and stimulates the angiogenic response of the host vasculature (Azoitei et al., 2010). Moreover, this isoform regulates tumor cell communication with ECs in gastrointestinal tumors and glioblastomas and promotes tumor growth. Mechanistically, PKD-2 integrates signals from hypoxia and HSP90 pathways in the NF- $\kappa$ B/VEGF signaling axis to stimulate angiogenesis and malignant progression (Azoitei et al., 2014). PKD2 is also able to promote pancreatic cancer cell invasion in three-dimensional extracellular matrix cultures by stimulating expression and secretion of matrix metalloproteinases 7 and 9 (MMP7/9) whereas MMP9 stimulates PKD2-mediated tumor angiogenesis by releasing extracellular matrix-bound VEGF and increasing its bioavailability (Wille et al., 2014).

\section{SUMMARY AND PROSPECTIVE}

PKD-1 regulates the expression of a variety of angiogenic genes. Interestingly, LPA/PKD-1 signaling suppresses CD36 transcription and reprograms MVECs for arteriogenic gene expression via a nuclear HDAC7-FoxO1 complex, implicating microvascular remodeling and tumor arteriogenesis (Kohlenberg et al., 2013; Ren et al., 2015). This not only indicates the plasticity of adult ECs but also suggests the role of PKD-1 in EC heterogeneity (Aird, 2012; Ren, 2015). The PKD-FoxO1 signaling axis may thus function as a molecular link for a dynamic balance between pro- and anti-angiogenic signaling by controlling EC CD36 transcription, possibly regulating arteriogenesis via this axis. Activation of this pathway in vivo may promote vascular remodeling and the functional stability of the arterial networks (Ren et al., 2016a). The precise mechanisms and functional consequences are worthy of future investigation.

Furthermore, PKD-1 signaling is essential for VEGF signaling-mediated angiogenic functions and is implicated in tumor arteriogenesis. VEGF signaling is regulated by the tight control of intracellular VEGFR2 localization (Bhattacharya et al., 2005; Lanahan et al., 2010). VEGF induces PKD-1 signaling and angiogenesis via regulation of $\alpha v \beta 3$ integrin recycling (Woods et al., 2004; White et al., 2007; di Blasio et al., 2010). Therefore, PKD-1 signaling might regulate VEGFR-2 trafficking, an important process of VEGF signaling and of arterial morphogenesis (Lanahan et al., 2010; Simons, 2012) via cross-talking with integrin $\alpha \mathrm{v} \beta 3$ and CD36, subsequently turning on angiogenic switch for arterial differentiation of ECs to promote arteriogenesis. ECs is essential for developmental and adult arteriogenesis (Ren et al., 2010; Simons and Eichmann, 2015) and EC PKD-1 signaling is essential for improving tissue perfusion through proarteriogenic reprogramming in the ischemic conditions(Ren et al., 2016b). It is important to understand how PKD-1 signaling interacts with FoxO1 and histone deacetylases to initiate an epigenetic and transcriptional program and control arteriogenic gene transcription and morphogenesis. This understanding will provide insight into finding new and effective therapeutic targets and strategies against cardiovascular disease, cancer, and obesity.

\section{AUTHOR CONTRIBUTIONS}

The author confirms being the sole contributor of this work and approved it for publication. 


\section{ACKNOWLEDGMENTS}

This work is supported by a National Scientific Development Grant (13SDG14800019) from the American Heart Association (BR), an Institutional Research Grant (\# 86-004-26) from

\section{REFERENCES}

Adams, R. H., and Alitalo, K. (2007). Molecular regulation of angiogenesis and lymphangiogenesis. Nat. Rev. Mol. Cell Biol. 8, 464-478. doi: 10.1038/ nrm2183

Aicart-Ramos, C., Sanchez-Ruiloba, L., Gomez-Parrizas, M., Zaragoza, C., Iglesias, T., and Rodriguez-Crespo, I. (2014). Protein kinase D activity controls endothelial nitric oxide synthesis. J. Cell. Sci. 127, 3360-3372. doi: $10.1242 /$ jcs. 148601

Aird, W. C. (2012). Endothelial cell heterogeneity. Cold Spring Harb. Perspect. Med. 2:a006429. doi: 10.1101/cshperspect.a006429

Altschmied, J., and Haendeler, J. (2008). A new kid on the block: PKD1: a promising target for antiangiogenic therapy? Arterioscler. Thromb. Vasc. Biol. 28, 1689-1690. doi: 10.1161/ATVBAHA.108.174250

Anderson, G., Chen, J., and Wang, Q. J. (2005). Individual C1 domains of PKD3 in phorbol ester-induced plasma membrane translocation of PKD3 in intact cells. Cell. Signal. 17, 1397-1411. doi: 10.1016/j.cellsig.2005.02.007

Avkiran, M., Rowland, A. J., Cuello, F., and Haworth, R. S. (2008). Protein kinase $\mathrm{d}$ in the cardiovascular system: emerging roles in health and disease. Circ. Res. 102, 157-163. doi: 10.1161/CIRCRESAHA.107.168211

Azoitei, N., Diepold, K., Brunner, C., Rouhi, A., Genze, F., Becher, A., et al. (2014). HSP90 supports tumor growth and angiogenesis through PRKD2 protein stabilization. Cancer Res. 74, 7125-7136. doi: 10.1158/0008-5472.CAN-14-1017

Azoitei, N., Pusapati, G. V., Kleger, A., Moller, P., Kufer, R., Genze, F., et al. (2010). Protein kinase D2 is a crucial regulator of tumour cell-endothelial cell communication in gastrointestinal tumours. Gut 59, 1316-1330. doi: 10.1136/gut.2009.206813

Bergers, G., and Benjamin, L. E. (2003). Tumorigenesis and the angiogenic switch. Nat. Rev. Cancer 3, 401-410. doi: 10.1038/nrc1093

Bhattacharya, R., Kang-Decker, N., Hughes, D. A., Mukherjee, P., Shah, V., McNiven, M. A., et al. (2005). Regulatory role of dynamin-2 in VEGFR-2/KDRmediated endothelial signaling. FASEB J. 19, 1692-1694. doi: 10.1096/fj.053889 fje

Burke, A. P., Farb, A., Malcom, G. T., Liang, Y. H., Smialek, J., and Virmani, R. (1997). Coronary risk factors and plaque morphology in men with coronary disease who died suddenly. N. Engl. J. Med. 336, 1276-1282. doi: 10.1056/NEJM199705013361802

Carmeliet, P. (2000). Mechanisms of angiogenesis and arteriogenesis. Nat. Med. 6, 389-395. doi: 10.1038/74651

Chang, S., Young, B. D., Li, S., Qi, X., Richardson, J. A., and Olson, E. N. (2006). Histone deacetylase 7 maintains vascular integrity by repressing matrix metalloproteinase 10. Cell 126, 321-334. doi: 10.1016/j.cell.2006.05.040

Chen, J., Deng, F., Singh, S. V., and Wang, Q. J. (2008). Protein kinase D3 (PKD3) contributes to prostate cancer cell growth and survival through a PKCepsilon/PKD3 pathway downstream of Akt and ERK 1/2. Cancer Res. 68, 3844-3853. doi: 10.1158/0008-5472.CAN-07-5156

Chen, Y., Ramakrishnan, D. P., and Ren, B. (2013). Regulation of angiogenesis by phospholipid lysophosphatidic acid. Front. Biosci. 18, 852-861. doi: $10.2741 / 4148$

Comuzzie, A. G., Cole, S. A., Laston, S. L., Voruganti, V. S., Haack, K., Gibbs, R. A., et al. (2012). Novel genetic loci identified for the pathophysiology of childhood obesity in the Hispanic population. PLoS ONE 7:e51954. doi: 10.1371/journal.pone.0051954

di Blasio, L., Droetto, S., Norman, J., Bussolino, F., and Primo, L. (2010). Protein kinase D1 regulates VEGF-A-induced $\alpha v \beta 3$ integrin trafficking and endothelial cell migration. Traffic 11, 1107-1118. doi: 10.1111/j.1600-0854.2010. 01077.x

Dong, L., Yuan, Y., Aguilera-Barrantes, I., Chen, Y., Sturich, A., Yuan, R., et al. (2015). Abstract 482: signaling lipid lysophosphatidic acid is a critical link
American Cancer Society (BR), and a MCW Cancer Center fund (BR), and a Career Development Award from The Central Society of Clinical and Translational Research (BR). I appreciate Ms Shana Maker at Blood Research Institute for editing.

to diet-induced obesity, cellular bioenergetics and breast cancer angiogenesis. Arterioscler. Thromb. Vasc. Biol. 35(Suppl. 1), A482. Available online at: http:// atvb.ahajournals.org/content/35/Suppl_1/A482

Eiseler, T., Schmid, M. A., Topbas, F., Pfizenmaier, K., and Hausser, A. (2007). PKD is recruited to sites of actin remodelling at the leading edge and negatively regulates cell migration. FEBS Lett. 581, 4279-4287. doi: 10.1016/j.febslet.2007.07.079

Endo, K., Oki, E., Biedermann, V., Kojima, H., Yoshida, K., Johannes, F. J., et al. (2000). Proteolytic cleavage and activation of protein kinase C [micro] by caspase-3 in the apoptotic response of cells to 1- $\beta$-Darabinofuranosylcytosine and other genotoxic agents. J. Biol. Chem. 275, 18476-18481. doi: 10.1074/jbc.M002266200

Evans, I. M., Bagherzadeh, A., Charles, M., Raynham, T., Ireson, C., Boakes, A., et al. (2010). Characterization of the biological effects of a novel protein kinase D inhibitor in endothelial cells. Biochem. J. 429, 565-572. doi: 10.1042/BJ20100578

Evans, I. M., Britton, G., and Zachary, I. C. (2008). Vascular endothelial growth factor induces heat shock protein (HSP) 27 serine 82 phosphorylation and endothelial tubulogenesis via protein kinase $\mathrm{D}$ and independent of $\mathrm{p} 38$ kinase. Cell. Signal. 20, 1375-1384. doi: 10.1016/j.cellsig.2008.03.002

Ferrara, N., Gerber, H. P., and LeCouter, J. (2003). The biology of VEGF and its receptors. Nat. Med. 9, 669-676. doi: 10.1038/nm0603-669

Fielitz, J., Kim, M. S., Shelton, J. M., Qi, X., Hill, J. A., Richardson, J. A., et al. (2008). Requirement of protein kinase D1 for pathological cardiac remodeling. Proc. Natl. Acad. Sci. U.S.A. 105, 3059-3063. doi: 10.1073/pnas.07122 65105

Folkman, J., and Kalluri, R. (2004). Cancer without disease. Nature 427, 787. doi: $10.1038 / 427787 \mathrm{a}$

Fu, Y., and Rubin, C. S. (2011). Protein kinase D: coupling extracellular stimuli to the regulation of cell physiology. Embo Rep. 12, 785-796. doi: 10.1038/embor.2011.139

Guha, S., Tanasanvimon, S., Sinnett-Smith, J., and Rozengurt, E. (2010). Role of protein kinase D signaling in pancreatic cancer. Biochem. Pharmacol. 80, 1946-1954. doi: 10.1016/j.bcp.2010.07.002

Ha, C. H., Jhun, B. S., Kao, H. Y., and Jin, Z. G. (2008a). VEGF stimulates HDAC7 phosphorylation and cytoplasmic accumulation modulating matrix metalloproteinase expression and angiogenesis. Arterioscler. Thromb. Vasc. Biol. 28, 1782-1788. doi: 10.1161/ATVBAHA.108.172528

Ha, C. H., Wang, W., Jhun, B. S., Wong, C., Hausser, A., Pfizenmaier, K., et al. (2008b). Protein kinase D-dependent phosphorylation and nuclear export of histone deacetylase 5 mediates vascular endothelial growth factor-induced gene expression and angiogenesis. J. Biol. Chem. 283, 14590-14599. doi: 10.1074/jbc.M800264200

Haberland, M., Montgomery, R. L., and Olson, E. N. (2009). The many roles of histone deacetylases in development and physiology: implications for disease and therapy. Nat. Rev. Genet. 10, 32-42. doi: 10.1038/nrg2485

Hamik, A., Wang, B., and Jain, M. K. (2006). Transcriptional regulators of angiogenesis. Arterioscler. Thromb. Vasc. Biol. 26, 1936-1947. doi: 10.1161/01.ATV.0000232542.42968.e3

Hanahan, D., and Weinberg, R. A. (2011). Hallmarks of cancer: the next generation. Cell 144, 646-674. doi: 10.1016/j.cell.2011.02.013

Hao, Q., Wang, L., and Tang, H. (2009a). Vascular endothelial growth factor induces protein kinase $\mathrm{D}$-dependent production of proinflammatory cytokines in endothelial cells. Am. J. Physiol. Cell Physiol. 296, C821-C827. doi: 10.1152/ajpcell.00504

Hao, Q., Wang, L., Zhao, Z. J., and Tang, H. (2009b). Identification of protein kinase D2 as a pivotal regulator of endothelial cell proliferation, migration, and angiogenesis. J. Biol. Chem. 284, 799-806. doi: 10.1074/jbc.M8075 46200 
Hollenbach, M., Stoll, S. J., Jorgens, K., Seufferlein, T., and Kroll, J. (2013). Different regulation of physiological and tumor angiogenesis in zebrafish by protein kinase D1 (PKD1). PLoS ONE 8:e68033. doi: 10.1371/journal.pone.0068033

Hong, C. C., Peterson, Q. P., Hong, J. Y., and Peterson, R. T. (2006). Artery/vein specification is governed by opposing phosphatidylinositol-3 kinase and MAP kinase/ERK signaling. Curr. Biol. 16, 1366-1372. doi: 10.1016/j.cub.2006. 05.046

Huang, H., Amin, V., Gurin, M., Wan, E., Thorp, E., Homma, S., et al. (2013). Diet-induced obesity causes long QT and reduces transcription of voltage-gated potassium channels. J. Mol. Cell. Cardiol. 59, 151-158. doi: 10.1016/j.yjmcc.2013.03.007

Huck, B., Duss, S., Hausser, A., and Olayioye, M. A. (2014). Elevated protein kinase D3 (PKD3) expression supports proliferation of triple-negative breast cancer cells and contributes to mTORC1-S6K1 pathway activation. J. Biol. Chem. 289, 3138-3147. doi: 10.1074/jbc.M113.502633

Huck, B., Kemkemer, R., Franz-Wachtel, M., Macek, B., Hausser, A., and Olayioye, M. A. (2012). GIT1 phosphorylation on serine 46 by PKD3 regulates paxillin trafficking and cellular protrusive activity. J. Biol. Chem. 287, 34604-34613. doi: 10.1074/jbc.M112.374652

Iglesias, T., Waldron, R. T., and Rozengurt, E. (1998). Identification of in vivo phosphorylation sites required for protein kinase D activation. J. Biol. Chem. 273, 27662-27667. doi: $10.1074 /$ jbc.273.42.27662

Ismail, H., Mofarrahi, M., Echavarria, R., Harel, S., Verdin, E., Lim, H. W., et al. (2012). Angiopoietin-1 and vascular endothelial growth factor regulation of leukocyte adhesion to endothelial cells: role of nuclear receptor-77. Arterioscler. Thromb. Vasc. Biol. 32, 1707-1716. doi: 10.1161/ATVBAHA.112.251546

Jamora, C., Yamanouye, N., Van Lint, J., Laudenslager, J., Vandenheede, J. R., Faulkner, D. J., et al. (1999). G $\beta \gamma$-mediated regulation of Golgi organization is through the direct activation of protein kinase D. Cell 98, 59-68. doi: 10.1016/S0092-8674(00)80606-6

Kohlenberg, J., Chen, Y., Best, B., Storz, P., Peterson, R. T., Silverstein, R., et al. (2013). A novel LPA-PKD1-FoxO1 pathway in endothelial cells provides an angiogenic switch via down-regulation of CD36 transcription and induction of arteriogenic responses. Cancer Res. 73:LB-338. doi: 10.1158/15387445.AM2013-LB-338

Lanahan, A. A., Hermans, K., Claes, F., Kerley-Hamilton, J. S., Zhuang, Z. W., Giordano, F. J., et al. (2010). VEGF receptor 2 endocytic trafficking regulates arterial morphogenesis. Dev. Cell 18, 713-724. doi: 10.1016/j.devcel.2010.02.016

LaValle, C. R., Bravo-Altamirano, K., Giridhar, K. V., Chen, J., Sharlow, E., Lazo, J. S., et al. (2010a). Novel protein kinase D inhibitors cause potent arrest in prostate cancer cell growth and motility. BMC Chem. Biol. 10:5. doi: 10.1186/1472-6769-10-5

LaValle, C. R., George, K. M., Sharlow, E. R., Lazo, J. S., Wipf, P., and Wang, Q. J. (2010b). Protein kinase D as a potential new target for cancer therapy. Biochim. Biophys. Acta 1806, 183-192. doi: 10.1016/j.bbcan.2010.05.003

Lawson, N. D., Mugford, J. W., Diamond, B. A., and Weinstein, B. M. (2003). phospholipase C gamma-1 is required downstream of vascular endothelial growth factor during arterial development. Genes Dev. 17, 1346-1351. doi: 10.1101/gad.1072203

Lencz, T., and Malhotra, A. K. (2015). Targeting the schizophrenia genome: a fast track strategy from GWAS to clinic. Mol. Psychiatry 20, 820-826. doi: 10.1038/mp.2015.28

Lint, J. V., Rykx, A., Vantus, T., and Vandenheede, J. R. (2002). Getting to know protein kinase D. Int. J. Biochem. Cell Biol. 34, 577-581. doi: 10.1016/S13572725(01)00163-7

Liu, D., Evans, I., Britton, G., and Zachary, I. (2008). The zinc-finger transcription factor, early growth response 3 , mediates VEGF-induced angiogenesis. Oncogene 27, 2989-2998. doi: 10.1038/sj.onc.1210959

Manning, G., Whyte, D. B., Martinez, R., Hunter, T., and Sudarsanam, S. (2002). The protein kinase complement of the human genome. Science 298, 1912-1934. doi: $10.1126 /$ science. 1075762

Matsumoto, T., and Claesson-Welsh, L. (2001). VEGF receptor signal transduction. Sci. STKE 2001:re21. doi: 10.1126/stke.2001.112.re21

Matthews, S. A., Iglesias, T., Rozengurt, E., and Cantrell, D. (2000). Spatial and temporal regulation of protein kinase D (PKD). EMBO J. 19, 2935-2945. doi: $10.1093 / \mathrm{emboj} / 19.12 .2935$
Matthews, S. A., Navarro, M. N., Sinclair, L. V., Emslie, E., Feijoo-Carnero, C., and Cantrell, D. A. (2010). Unique functions for protein kinase D1 and protein kinase D2 in mammalian cells. Biochem. J. 432, 153-163. doi: 10.1042/BJ20101188

Matthews, S. A., Rozengurt, E., and Cantrell, D. (1999). Characterization of serine 916 as an in vivo autophosphorylation site for protein kinase D/Protein kinase Cmu. J. Biol. Chem. 274, 26543-26549. doi: 10.1074/jbc.274.37.26543

Mottet, D., Bellahcene, A., Pirotte, S., Waltregny, D., Deroanne, C., Lamour, V., et al. (2007). Histone deacetylase 7 silencing alters endothelial cell migration, a key step in angiogenesis. Circ. Res. 101, 1237-1246. doi: 10.1161/CIRCRESAHA.107.149377

Moulton, K. S., Heller, E., Konerding, M. A., Flynn, E., Palinski, W., and Folkman, J. (1999). Angiogenesis inhibitors endostatin or TNP-470 reduce intimal neovascularization and plaque growth in apolipoprotein E-deficient mice. Circulation 99, 1726-1732. doi: 10.1161/01.CIR.99. 13.1726

Moulton, K. S., Olsen, B. R., Sonn, S., Fukai, N., Zurakowski, D., and Zeng, X. (2004). Loss of collagen XVIII enhances neovascularization and vascular permeability in atherosclerosis. Circulation 110, 1330-1336. doi: 10.1161/01.CIR.0000140720.79015.3C

Moulton, K. S., Vakili, K., Zurakowski, D., Soliman, M., Butterfield, C., Sylvin, E., et al. (2003). Inhibition of plaque neovascularization reduces macrophage accumulation and progression of advanced atherosclerosis. Proc. Natl. Acad. Sci. U.S.A. 100, 4736-4741. doi: 10.1073/pnas.0730843100

Ochi, N., Tanasanvimon, S., Matsuo, Y., Tong, Z., Sung, B., Aggarwal, B. B., et al. (2011). Protein kinase D1 promotes anchorage-independent growth, invasion, and angiogenesis by human pancreatic cancer cells. J. Cell. Physiol. 226, 1074-1081. doi: 10.1002/jcp.22421

Parra, M., Kasler, H., McKinsey, T. A., Olson, E. N., and Verdin, E. (2005). Protein kinase D1 phosphorylates HDAC7 and induces its nuclear export after T-cell receptor activation. J. Biol. Chem. 280, 13762-13770. doi: 10.1074/jbc.M413396200

Prigozhina, N. L., and Waterman-Storer, C. M. (2004). Protein kinase D-mediated anterograde membrane trafficking is required for fibroblast motility. Curr. Biol. 14, 88-98. doi: 10.1016/j.cub.2004.01.003

Qin, L., Zeng, H., and Zhao, D. (2006). Requirement of protein kinase D tyrosine phosphorylation for VEGF-A165-induced angiogenesis through its interaction and regulation of phospholipase Cgamma phosphorylation. J. Biol. Chem. 281, 32550-32558. doi: 10.1074/jbc.M604853200

Ren, B. (2015). Endothelial Cells: a key player in angiogenesis and lymphangiogenesis. MOJ Cell Sci. Rep. 2:00015. doi: 10.15406/mojcsr.2015. 02.00015

Ren, B., Best, B., Ramakrishnan, D. P., Walcott, B., Storz, P., and Silverstein, R. L. (2016a). LPA/PKD-1-FOXO1 signaling axis mediates endothelial cell cd36 transcriptional repression and proangiogenic and proarteriogenic reprogramming. Arterioscler. Thromb. Vasc. Biol. doi: 10.1161/ATVBAHA.116.307421. [Epub ahead of print].

Ren, B., Best, B., Ramakrishnan, D., Walcott, B., Storz, P., and Silverstein, R. (2015). Abstract 7: LPA/PKD-1-HDAC7-FoxO1 signaling-mediated endothelial cd36 transcriptional repression and proarteriogenic reprogramming. Arterioscler. Thromb. Vasc. Biol. 35(Suppl. 1), A7. Available online at: http://atvb. ahajournals.org/content/35/Suppl_1/A7.abstract

Ren, B., Deng, Y., Mukhopadhyay, A., Lanahan, A. A., Zhuang, Z. W., Moodie, K. L., et al. (2010). ERK1/2-Akt1 crosstalk regulates arteriogenesis in mice and zebrafish. J. Clin. Invest. 120, 1217-1228. doi: 10.1172/JCI39837

Ren, B., Hale, J., Srikanthan, S., and Silverstein, R. L. (2011). Lysophosphatidic acid suppresses endothelial cell CD36 expression and promotes angiogenesis via a PKD-1-dependent signaling pathway. Blood 117, 6036-6045. doi: 10.1182/blood-2010-12-326017

Ren, B., Hoti, N., Rabasseda, X., Wang, Y. Z., and Wu, M. (2003). The antiangiogenic and therapeutic implications of endostatin. Methods Find. Exp. Clin. Pharmacol. 25, 215-224. doi: 10.1358/mf.2003.25.3.769643

Ren, B., Ramakrishnan, D. P., Walcott, B., Chen, Y., Best, B., Storz, P., et al. (2014). Abstract 565: LPA-PKD-1-HDAC7/NCoR1-FoxO1 signaling axis regulates endothelial cell $\operatorname{cd} 36$ transcription and stimulates arteriogenic responses. Arterioscler. Thromb. Vasc. Biol. 34(Suppl. 1), A565. Available online at: http:// atvb.ahajournals.org/content/34/Suppl_1/A565 
Ren, B., Silverstein, R., Yuan, R., and Dong, L. (2016b). Endothelial cell protein kinase D1 signaling is essential for improving tissue ischemia via arteriotenic reprogramming. J. Invest. Med. 64, 915-915. doi: 10.1136/jim-2016-000120.8

Ren, B., Song, K., Parangi, S., Jin, T., Ye, M., Humphreys, R., et al. (2009). A double hit to kill tumor and endothelial cells by TRAIL and antiangiogenic 3TSR. Cancer Res. 69, 3856-3865. doi: 10.1158/0008-5472.CAN-08-2940

Ren, B., Wang, Y., Rabasseda, X., and Wang, Y. Z. (2002). Recombinant human endostatin is beneficial to endothelial cell growth exposed to mildly oxidized low-density lipoproteins. Methods Find. Exp. Clin. Pharmacol. 24, 195-199. doi: 10.1358/mf.2002.24.4.678450

Ren, B., Yee, K. O., Lawler, J., and Khosravi-Far, R. (2006). Regulation of tumor angiogenesis by thrombospondin-1. Biochim. Biophys. Acta 1765, 178-188. doi: 10.1016/j.bbcan.2005.11.002

Rivera-Lopez, C. M., Tucker, A. L., and Lynch, K. R. (2008). Lysophosphatidic acid (LPA) and angiogenesis. Angiogenesis 11, 301-310. doi: 10.1007/s10456-0089113-5

Rozengurt, E. (2011). Protein kinase D signaling: multiple biological functions in health and disease. Physiology 26, 23-33. doi: 10.1152/physiol.00037.2010

Rozengurt, E., Rey, O., and Waldron, R. T. (2005). Protein kinase D signaling. J. Biol. Chem. 280, 13205-13208. doi: 10.1074/jbc.R500002200

Rykx, A., De Kimpe, L., Mikhalap, S., Vantus, T., Seufferlein, T., Vandenheede, J. R., et al. (2003). Protein kinase D: a family affair. FEBS Lett. 546, 81-86. doi: 10.1016/S0014-5793(03)00487-3

Semenza, G. L. (2007). Vasculogenesis, angiogenesis, and arteriogenesis: mechanisms of blood vessel formation and remodeling. J. Cell. Biochem. 102, 840-847. doi: 10.1002/jcb.21523

Shin, S., Wolgamott, L., and Yoon, S. O. (2012). Regulation of endothelial cell morphogenesis by the protein kinase D (PKD)/glycogen synthase kinase 3 (GSK3) $\beta$ pathway. Am. J. Physiol. Cell Physiol. 303, C743-756. doi: 10.1152/ajpcell.00442.2011

Simons, M. (2012). An inside view: VEGF receptor trafficking and signaling. Physiology 27, 213-222. doi: 10.1152/physiol.00016.2012

Simons, M., and Eichmann, A. (2015). Molecular controls of arterial morphogenesis. Circ. Res. 116, 1712-1724. doi: 10.1161/CIRCRESAHA.116. 302953

Speliotes, E. K., Willer, C. J., Berndt, S. I., Monda, K. L., Thorleifsson, G., Jackson, A. U., et al. (2010). Association analyses of 249,796 individuals reveal 18 new loci associated with body mass index. Nat. Genet. 42, 937-948. doi: $10.1038 /$ ng.686

Steinberg, S. F. (2012). Regulation of protein kinase D1 activity. Mol. Pharmacol. 81, 284-291. doi: 10.1124/mol.111.075986

Storz, P., Doppler, H., and Toker, A. (2005). Protein kinase D mediates mitochondrion-to-nucleus signaling and detoxification from mitochondrial reactive oxygen species. Mol. Cell. Biol. 25, 8520-8530. doi: 10.1128/MCB.25.19.8520-8530.2005

Tinsley, J. H., Teasdale, N. R., and Yuan, S. Y. (2004). Involvement of PKC $\delta$ and PKD in pulmonary microvascular endothelial cell hyperpermeability. Am. J. Physiol. Cell Physiol. 286, C105-C111. doi: 10.1152/ajpcell.00340.2003

Tirziu, D., Jaba, I. M., Yu, P., Larrivee, B., Coon, B. G., Cristofaro, B., et al. (2012). Endothelial nuclear factor-kappaB-dependent regulation of arteriogenesis and branching. Circulation 126, 2589-2600. doi: 10.1161/CIRCULATIONAHA.112.119321

Urbich, C., Rossig, L., Kaluza, D., Potente, M., Boeckel, J. N., Knau, A., et al. (2009). HDAC5 is a repressor of angiogenesis and determines the angiogenic gene expression pattern of endothelial cells. Blood 113, 5669-5679. doi: 10.1182/blood-2009-01-196485

von Wichert, G., Edenfeld, T., von Blume, J., Krisp, H., Krndija, D., Schmid, H., et al. (2008). Protein kinase D2 regulates chromogranin A secretion in human BON neuroendocrine tumour cells. Cell. Signal. 20, 925-934. doi: 10.1016/j.cellsig.2008.01.003
Waldron, R. T., and Rozengurt, E. (2003). Protein kinase C phosphorylates protein kinase D activation loop Ser744 and Ser748 and releases autoinhibition by the pleckstrin homology domain. J. Biol. Chem. 278, 154-163. doi: 10.1074/jbc.M208075200

Wang, Q. J. (2006). PKD at the crossroads of DAG and PKC signaling. Trends Pharmacol. Sci. 27, 317-323. doi: 10.1016/j.tips.2006.04.003

Wang, S., Li, X., Parra, M., Verdin, E., Bassel-Duby, R., and Olson, E. N. (2008). Control of endothelial cell proliferation and migration by VEGF signaling to histone deacetylase 7. Proc. Natl. Acad. Sci. U.S.A. 105, 7738-7743. doi: $10.1073 /$ pnas.0802857105

Wang, Y., and Rodrigues, B. (2015). Intrinsic and extrinsic regulation of cardiac lipoprotein lipase following diabetes. Biochim. Biophys. Acta 1851, 163-171. doi: 10.1016/j.bbalip.2014.11.007

White, D. P., Caswell, P. T., and Norman, J. C. (2007). $\alpha v \beta 3$ and $\alpha 5 \beta 1$ integrin recycling pathways dictate downstream Rho kinase signaling to regulate persistent cell migration. J. Cell Biol. 177, 515-525. doi: 10.1083/jcb.20060 9004

Wille, C., Kohler, C., Armacki, M., Jamali, A., Gossele, U., Pfizenmaier, K., et al. (2014). Protein kinase D2 induces invasion of pancreatic cancer cells by regulating matrix metalloproteinases. Mol. Biol. Cell 25, 324-336. doi: 10.1091/mbc.E13-06-0334

Wong, C., and Jin, Z. G. (2005). Protein kinase C-dependent protein kinase D activation modulates ERK signal pathway and endothelial cell proliferation by vascular endothelial growth factor. J. Biol. Chem. 280, 33262-33269. doi: 10.1074/jbc.M503198200

Wong, C. G., Rich, K. A., Liaw, L. H., Hsu, H. T., and Berns, M. W. (2001). Intravitreal VEGF and bFGF produce florid retinal neovascularization and hemorrhage in the rabbit. Curr. Eye Res. 22, 140-147. doi: 10.1076/ceyr.22.2.140.5528

Woods, A. J., White, D. P., Caswell, P. T., and Norman, J. C. (2004). $\mathrm{PKD} 1 / \mathrm{PKC} \mu$ promotes $\alpha \mathrm{v} \beta 3$ integrin recycling and delivery to nascent focal adhesions. EMBO J. 23, 2531-2543. doi: 10.1038/sj.emboj. 7600267

Yeaman, C., Ayala, M. I., Wright, J. R., Bard, F., Bossard, C., Ang, A., et al. (2004). Protein kinase D regulates basolateral membrane protein exit from trans-Golgi network. Nat. Cell Biol. 6, 106-112. doi: 10.1038/ncb1090

Yuan, L., Chan, G. C., Beeler, D., Janes, L., Spokes, K. C., Dharaneeswaran, H., et al. (2016). A role of stochastic phenotype switching in generating mosaic endothelial cell heterogeneity. Nat. Commun. 7:10160. doi: 10.1038/ncomms10160

Yuan, Y., Kohlenberg, J. D., Chen, Y., Komas, S., Xin, G., Yuan, G., et al. (2015). Abstract A09: Diet-induced obesity promotes breast cancer progression by LPA-signaling-mediated functional changes of mitochondria and angiogenesis. Cancer Res. 75(1 Suppl.), A09. doi: 10.1158/1538-7445.chtme 14-a09

Zhao, S., Zhou, L., Niu, G., Li, Y., Zhao, D., and Zeng, H. (2014). Differential regulation of orphan nuclear receptor TR3 transcript variants by novel vascular growth factor signaling pathways. FASEB J. 28, 4524-4533. doi: 10.1096/fj.13248401

Conflict of Interest Statement: The author declares that the research was conducted in the absence of any commercial or financial relationships that could be construed as a potential conflict of interest.

Copyright (c) 2016 Ren. This is an open-access article distributed under the terms of the Creative Commons Attribution License (CC BY). The use, distribution or reproduction in other forums is permitted, provided the original author(s) or licensor are credited and that the original publication in this journal is cited, in accordance with accepted academic practice. No use, distribution or reproduction is permitted which does not comply with these terms. 